\title{
Interactions between Antarctic sea ice and large-scale atmospheric modes in CMIP5 models
}

\author{
Serena Schroeter ${ }^{1,2,3}$, Will Hobbs ${ }^{3,2}$, and Nathaniel L. Bindoff $\mathbf{f}^{1,3,2,4}$ \\ ${ }^{1}$ Institute for Marine and Antarctic Studies (IMAS), University of Tasmania, Hobart, 7004, Australia \\ ${ }^{2}$ Australian Research Council Centre of Excellence for Climate System Science (ARCCSS), Hobart, 7004, Australia \\ ${ }^{3}$ Antarctic Climate and Ecosystems Cooperative Research Centre (ACE CRC), Hobart, 7004, Australia \\ ${ }^{4}$ CSIRO Oceans and Atmosphere, Hobart, 7004, Australia \\ Correspondence to: Serena Schroeter (serena.schroeter@utas.edu.au)
}

Received: 22 August 2016 - Discussion started: 30 January 2017

Revised: 4 October 2016 - Accepted: 13 February 2017 - Published: 24 March 2017

\begin{abstract}
The response of Antarctic sea ice to large-scale patterns of atmospheric variability varies according to sea ice sector and season. In this study, interannual atmosphere-sea ice interactions were explored using observations and reanalysis data, and compared with simulated interactions by models in the Coupled Model Intercomparison Project Phase 5 (CMIP5). Simulated relationships between atmospheric variability and sea ice variability generally reproduced the observed relationships, though more closely during the season of sea ice advance than the season of sea ice retreat. Atmospheric influence on sea ice is known to be strongest during advance, and it appears that models are able to capture the dominance of the atmosphere during advance. Simulations of ocean-atmosphere-sea ice interactions during retreat, however, require further investigation.

A large proportion of model ensemble members overestimated the relative importance of the Southern Annular Mode (SAM) compared with other modes of high southern latitude climate, while the influence of tropical forcing was underestimated. This result emerged particularly strongly during the season of sea ice retreat. The zonal patterns of the SAM in many models and its exaggerated influence on sea ice overwhelm the comparatively underestimated meridional influence, suggesting that simulated sea ice variability would become more zonally symmetric as a result. Across the seasons of sea ice advance and retreat, three of the five sectors did not reveal a strong relationship with a pattern of largescale atmospheric variability in one or both seasons, indicating that sea ice in these sectors may be influenced more strongly by atmospheric variability unexplained by the major atmospheric modes, or by heat exchange in the ocean.
\end{abstract}

\section{Introduction}

Antarctic sea ice extent has increased by approximately $1.5 \%$ per decade since satellite observations began in 1979 (Parkinson and Cavalieri, 2012; Turner et al., 2015). The small overall increase masks higher-magnitude regional and seasonal trends around the continent, most notably an increase of $3.9 \%$ per decade in the Ross Sea peaking during spring, and a decrease of $-3.4 \%$ per decade in the Amundsen and Bellingshausen seas peaking during autumn (Turner et al., 2015). By contrast, models in the Coupled Model Intercomparison Project Phase 5 (CMIP5) exhibit decreasing sea ice trends in all months (Turner et al., 2013a). The reasons for the disparity between observed and modelled trends are not yet well understood (Bindoff et al., 2013; Hobbs et al., 2016). A large proportion of the observed trends are thought to be driven by interactions between Antarctic sea ice and atmospheric processes such as wind (Liu et al., 2004; Raphael, 2007; Lefebvre and Goosse, 2008; Massom et al., 2008; Yuan and Li, 2008; Holland and Kwok, 2012; Matear et al., 2015), and it has been suggested that deficiencies in the model representation of atmospheric circulation may account for at least part of this disparity (Hosking et al., 2013; Mahlstein et al., 2013). The response of Antarctic sea ice to atmospheric forcing incorporates complex feedbacks and interactions between the atmosphere, sea ice, and ocean (Lefebvre and Goosse, 2008; Raphael and Hobbs, 2014; Matear et al., 2015), and measuring the extent to which these feedbacks and interactions are represented in global climate simulations could provide insight into the representation of sea ice trends and variability. 
The Southern Annular Mode (SAM) is the dominant mode of atmospheric variability in the Southern Hemisphere ( $\mathrm{SH}$; Gong and Wang, 1999; Limpasuvan and Hartmann, 1999; Thompson and Wallace, 2000; Marshall, 2003). It is a zonally symmetric atmospheric structure with pressure anomalies of opposing signs vacillating between the polar and midlatitudes of the SH (Karoly, 1990; Gong and Wang, 1999; Thompson and Wallace, 2000). The positive phase of SAM is characterized by a poleward shift and intensification of westerly circumpolar winds (Thompson et al., 2000; Marshall, 2003) which has previously been thought to increase the northward expansion (and greater areal coverage) of sea ice through Ekman transport (Hall and Visbeck, 2002; Sen Gupta and England, 2006), while simultaneously pushing warmer oceanic air masses from the north over the comparatively cold land of the Antarctic Peninsula (Thompson and Wallace, 2000; Marshall et al., 2006; van Lipzig et al., 2008). A trend has been observed of the SAM moving towards its high-index (positive) polarity, with negative pressure anomalies over the Antarctic continent and positive anomalies in the mid-latitudes (Thompson et al., 2000; Thompson and Solomon, 2002; Marshall, 2003; Fogt et al., 2009). This trend is associated with stratospheric ozone depletion and forcing by greenhouse gases (Gillett and Thompson, 2003; Thompson et al., 2011; Ferreira et al., 2015). However, it has been recently suggested that the response of the Southern Ocean surface to a sustained SAM trend is more complex than the interannual Ekman response, whereby an initial sea ice expansion is followed by warming over the longer term caused by upwelling of relatively warm, mixed-layer ocean water (Marshall et al., 2014; Ferreira et al., 2015; Armour et al., 2016).

The Amundsen, Bellingshausen, Ross, and Weddell seas fall within a zone of orography that is non-axisymmetric, and experiences the highest mean sea level pressure variability in the SH (Lachlan-Cope et al., 2001). A climatological low-pressure centre within the circumpolar atmospheric trough south of $60^{\circ} \mathrm{S}$, known as the Amundsen Sea Low (ASL), plays a significant role in driving the advance and retreat of sea ice in this region (Hosking et al., 2013; Turner et al., 2013b, 2016; Fogt and Wovrosh, 2015; Raphael et al., 2015). The depth and longitudinal location of the ASL, which influence sea ice, are in turn influenced by tropical forcing (Yuan and Martinson, 2001; Ding et al., 2011; Schneider et al., 2011; Fogt and Wovrosh, 2015; Raphael et al., 2015), radiative forcing (Fogt and Wovrosh, 2015; Raphael et al., 2015), and the phase of the SAM (Lefebvre et al., 2004; Turner et al., 2013b). The contrasting sea ice trends of the Amundsen, Bellingshausen, and Ross seas are associated with the deepening of the ASL in recent decades (Turner et al., 2013b). Recent studies have suggested that trends in the ASL and associated winds affecting sea ice in these regions are within the bounds of modelled intrinsic variability (Turner et al., 2015, 2016).
The other major modes of climate variability are the two Pacific South American modes (PSA1 and PSA2), which are associated with the high-latitude atmospheric response to ENSO (Karoly, 1989; Mo, 2000; Mo and Paegle, 2001). ENSO is teleconnected to the southern polar latitudes through meridional circulation anomalies (Harangozo, 2000), and is known to impact Antarctic sea ice (Simmonds and Jacka, 1995; Kwok and Comiso, 2002; Turner, 2004; Yuan, 2004; Simpkins et al., 2012). However, evidence suggests that ENSO is only able to strongly influence the Antarctic climate during periods where SAM is relatively weak, or that an in-phase relationship exists between the PSA modes and the SAM, such as when the warm (cold) ENSO phase coincides with a negative (positive) SAM (Fogt and Bromwich, 2006; Stammerjohn et al., 2008; Fogt et al., 2010). This enables the ENSO to project onto the SAM and the two act synergistically to enhance pressure anomalies that influence Antarctic sea ice (Karoly, 1989; Fogt and Bromwich, 2006; Stammerjohn et al., 2008; Bernades Pezza et al., 2012). The high-latitude atmospheric response to ENSO is linked to sea ice anomalies in the Amundsen, Bellingshausen, Ross, and Weddell seas (Karoly, 1989; Harangozo, 2000; Kwok and Comiso, 2002; Yuan, 2004; Stammerjohn et al., 2008; Bernades Pezza et al., 2012), with recent work indicating that trends in the South Pacific ice edge during winter can be explained by changes in ice drift and surface winds resulting from a positive trend in the Southern Oscillation Index (Kwok et al., 2016).

While these large-scale atmospheric modes clearly show a strong influence on the observed variability of Antarctic sea ice, whether the representation of atmospheric modes in CMIP5 models can explain the disparity between observed and modelled sea ice trends remains uncertain. Some observational studies have concluded that the dominant modes, SAM and ENSO, cannot account for regional Antarctic sea ice trends, and that lesser-understood large-scale modes or local processes should be investigated as alternative drivers (Liu et al., 2004; Yu et al., 2011; Hobbs et al., 2016). Other recent studies have shown that sea ice around Antarctica, except in the Amundsen, Bellingshausen, and Ross sea regions, is not in fact influenced to a great extent by largescale atmospheric modes, but is most impacted by synoptic weather (Matear et al., 2015; Kohyama and Hartmann, 2016). It is also unlikely that a single climate process or driver can explain all regional and seasonal sea ice trends (Lefebvre and Goosse, 2008; Holland, 2014; Raphael and Hobbs, 2014). Exploring the simulated interactions between atmospheric variability and Antarctic sea ice variability can provide further clarification as to which sectors of sea ice are most strongly influenced by large-scale atmospheric modes, and whether the strength of representation of these interactions leads to more accurate simulations of Antarctic sea ice trends.

This study explores the extent to which global climate models reproduce large-scale patterns of atmospheric vari- 
ability as well as the influence of these patterns on Antarctic sea ice variability. Previous analyses of Antarctic sea ice have generally delineated sea ice sectors by oceanographic and meteorological boundaries (Zwally et al., 1983, Figs. 2 and 3; Parkinson and Cavalieri, 2012, Fig. 2). However, Raphael and Hobbs (2014) used spatial autocorrelation to calculate boundaries for independent sectors of Antarctic sea ice variability to define sectors where the sea ice is strongly correlated with neighbouring sea ice, indicating distinct sea ice regimes. The same study also calculated the average annual cycles of sea ice in each sector, revealing regionally distinct climatologies which, when aggregated to monthly intervals, produced seasons of sea ice advance (March-August) and retreat (October-February). Sea ice advance and retreat have been shown to be the key periods during which sea ice interacts with the atmosphere, and are more suitable for atmosphere-sea ice analysis than the traditional atmospheric seasons used in many studies (Stammerjohn et al., 2008; Renwick et al., 2012). Indeed, recent studies of change in Antarctic sea ice seasonality have concentrated on the seasons of annual advance, retreat, and duration of sea ice coverage, with the annual sea ice season calculated between the sea ice minimum of one year to the next (February-February) (Stammerjohn et al., 2012; Massom et al., 2013). This study extends the results of Raphael and Hobbs (2014), based on observed interactions between large-scale atmospheric circulation and different sectors of Antarctic sea ice during the seasons of sea ice advance and retreat, by comparing these with simulated interactions in CMIP5 climate models in the same sectors and during the same seasons. Establishing the extent to which the CMIP5 models produce simulated atmosphere-sea ice interactions that closely reflect observed interactions provides insight into whether large-scale patterns of variability are responsible for driving regional sea ice trends around Antarctica.

\section{Data}

Monthly Goddard-merged sea ice concentration data on a $25 \times 25 \mathrm{~km}$ grid were obtained from the National Snow and Ice Data Center (NSIDC) for the period March 1979 to February 2014 (Meier et al., 2015). These sea ice data were then interpolated from their native grid onto a grid of $0.5^{\circ}$ longitude by $0.25^{\circ}$ latitude, equating to approximately $25 \mathrm{~km}^{2}$ at $60^{\circ} \mathrm{S}$. From the regridded data, sea ice extent (SIE) was calculated from the total sea ice coverage for each degree of longitude, bounded by the coast and the $15 \%$ sea ice concentration isoline. Monthly mean sea level pressure (SLP) data from the ERA-Interim global atmospheric reanalysis from March 1979 to February 2014 were obtained from the European Centre for Medium-Range Weather Forecasts (available at http://apps.ecmwf.int/). ERA-Interim was chosen from the range of global atmospheric reanalysis products due to the consistency of its surface air temperature and surface temperature trend patterns with sea ice trends (Bromwich et al., 2011; Hobbs et al., 2016). ERA-Interim reanalysis assimilates observed data sequentially in $12 \mathrm{~h}$ cycles, combining new data in each cycle with a forecast model estimate of the global atmosphere and surface based on calculations from data in the previous cycle (Dee et al., 2011).

Monthly model sea ice area fraction (SIC), sea ice thickness (SIT), and SLP data from CMIP5 (Taylor et al., 2009, 2012) were obtained from the CMIP5 multi-model ensemble archive at the Program for Climate Model Diagnosis and Intercomparison (PCMDI). The full names and modelling institutions for the models used in this study are shown in Table 1. Model SIE was calculated over grid cells with at least $15 \%$ SIC and $20 \mathrm{~cm}$ SIT. Output from both the preindustrial control (piControl) and 20th century (historical) experiments were used. The piControl experiment, run for at least 500 years after the spin-up period in which model conditions are stabilized, applies a prescribed pre-industrial atmosphere that does not evolve over time, enabling examination of internal variability within the models (Taylor et al., 2009). The historical experiment runs from 1850 to at least 2005, and applies evolving climate forcings including aerosol emissions, changes to atmospheric composition from greenhouse gases, and solar forcing.

\section{Methods}

To prepare the data sets to produce observed atmospheresea ice interactions, we sliced ERA-Interim reanalysis SLP data (south of $50^{\circ} \mathrm{S}$ ) and observed SIE data for each year between 1979 and 2014 into the seasons of sea ice advance (March-August) and retreat (October-February) based on the analysis of Raphael and Hobbs (2014). We then weighted these seasonal data sets according to the length of each month during the season. The SIE season data was integrated to produce the five sectors of Raphael and Hobbs (2014): East Antarctica (71-163 E), Ross/Amundsen (163$\left.250^{\circ} \mathrm{E}\right)$, Amundsen/Bellingshausen $\left(250-293^{\circ} \mathrm{E}\right)$, Weddell $\left(293-346^{\circ} \mathrm{E}\right)$, and King Hakon VII $\left(346-71^{\circ} \mathrm{E}\right)$. We detrended both data sets and applied a cosine latitude weighting to the SLP data to compensate for the convergence of meridians. A two-sided $t$ test was used to determine statistical significance in the reanalysis correlations, and we masked out any correlations that were not significant at the 0.05 confidence (autocorrelation in climate data can lead to an overestimate of statistical significance, e.g. Zwiers and von Storch, 1995; however, the data were tested for autocorrelation, and at the timescales used in this analysis no autocorrelation was found). This approach differs from Raphael and Hobbs (2014) by the masking of insignificant values, weighted seasonal averaging, and the use of SLP instead of geopotential height. We applied the same processing to the models' piControl SIE and SLP fields. 
Table 1. Summary of models from CMIP5 used in the study, showing the institution/modelling centre and official model name.

\begin{tabular}{|c|c|}
\hline Institution/modelling centre & Model name \\
\hline $\begin{array}{l}\text { Commonwealth Scientific and Industrial Research Organization (CSIRO) } \\
\text { and Bureau of Meteorology (BOM), Australia }\end{array}$ & $\begin{array}{l}\text { ACCESS1.0, ACCESS1.3 } \\
\text { (Bi et al., 2013) }\end{array}$ \\
\hline Beijing Climate Center, China Meteorological Administration & BCC-CSM1.1 (Xiao-Ge et al., 2013) \\
\hline Canadian Centre for Climate Modelling and Analysis & CanESM2 (Arora et al., 2011) \\
\hline National Center for Atmospheric Research & CCSM4 (Gent et al., 2011) \\
\hline Community Earth System Model Contributors & CESM1-CAM5 (Neale, 2010) \\
\hline $\begin{array}{l}\text { Centre National de Recherches Météorologiques/Centre Européen } \\
\text { de Recherche et Formation Avancée en Calcul Scientifique }\end{array}$ & CNRM-CM5 (Voldoire et al., 2013) \\
\hline $\begin{array}{l}\text { LASG, Institute of Atmospheric Physics, Chinese Academy of } \\
\text { Sciences and CESS, Tsinghua University }\end{array}$ & FGOALS-g2 (Li et al., 2013) \\
\hline NOAA Geophysical Fluid Dynamics Laboratory & GFDL-CM3 (Griffies et al., 2011) \\
\hline Institut Pierre-Simon Laplace & $\begin{array}{l}\text { IPSL-CM5A-LR, IPSL-CM5A-MR } \\
\text { (Mignot and Bony, 2013) }\end{array}$ \\
\hline $\begin{array}{l}\text { Atmosphere and Ocean Research Institute (The University of Tokyo), } \\
\text { National Institute for Environmental Studies, and Japan Agency } \\
\text { for Marine-Earth Science and Technology }\end{array}$ & MIROC5 (Watanabe et al., 2010) \\
\hline Max-Planck-Institut für Meteorologie & MPI-ESM-LR, MPI-ESM-MR \\
\hline (Max Planck Institute for Meteorology) & (Jungclaus et al., 2013) \\
\hline Meteorological Research Institute & MRI-CGCM3 (Yukimoto et al., 2012) \\
\hline Norwegian Climate Centre & NorESM1-M (Bentsen et al., 2013) \\
\hline
\end{tabular}

The piControl experiment was chosen to isolate the unforced variability in the models. Sector-integrated SIE was then correlated with SLP for each season in both reanalysis and model data sets, producing correlation maps. These correlation maps acted as a proxy for both observed and simulated SIE-SLP relationships, showing the pattern of atmospheric variability that most influences sea ice in each sector. We then calculated a pattern correlation between the observed and simulated correlation maps during advance and retreat. The pattern correlation metrics indicated the agreement between the observations and the models' representations of SIE-SLP interactions for each sector and season.

In order to show whether a relationship existed between simulated trends of SIE and simulated SIE-SLP interactions, historical CMIP5 SIE data were averaged to create an ensemble mean SIE for each model, and sliced into the sea ice sectors described above. An ordinary least squares regression was then calculated for each sea ice sector between January 1979 and December 2005. The ensemble mean historical SIE sector trend for each model was plotted against the piControl pattern correlation metric for the same model to compare SIE trends to representation of observed atmosphere-sea ice interactions.

We also investigated the dominant observed and simulated modes of large-scale atmospheric variability over the SH. The monthly climatology was removed from SLP data for both ERA-Interim and model data from the historical experiment, which were then sliced into the seasons of sea ice advance and retreat for each year (1979-2014 for ERA-Interim, 1979-2005 for the models) as above. An empirical orthogo- nal function (EOF) analysis was conducted on the detrended and cosine-weighted seasonal data to produce the three leading eigenvectors, and their associated principal component time series. The same calculations were conducted upon a reanalysis time series between 1979 and 2005 to investigate whether a qualitative difference was evident between a shorter and longer time span, but the results remained largely the same (Fig. S1 in the Supplement). This indicates that the shorter model time span is representative of the full 19792014 period. As the two PSA modes both depict aspects of tropical teleconnections to the high latitudes, these modes were added together to create a single mode that describes the influence of tropical forcing on the Antarctic climate. The results are thus presented as from two modes: the first mode (SAM) and the combined second and third modes (PSA). Individual model ensemble member EOFs were then patterncorrelated with the corresponding EOFs of the reanalysis. The resulting correlation value for each model ensemble member indicated the extent to which the simulated pattern reflected the observed pattern for each of the eigenvectors. The percentage of variance explained by the simulated pattern was compared to the percentage of variance explained by the reanalysis. A $1: 1$ ratio indicated good agreement between the ensemble and the reanalysis, with a higher or lower ratio indicating an overestimation or underestimation of the importance of that eigenvector in the model. The variance of each principal component time series of both ERA-Interim and the CMIP5 ensemble members was recorded and plotted for comparison. 
Lastly, we analysed the observed relationships between anomalies of SIE and changes in the amplitude of each large-scale atmospheric mode, and whether models reasonably reproduced these relationships. The long-term climatological mean was removed from NSIDC SIE data to reveal SIE anomalies by longitude. These SIE anomalies were then cross-correlated with each reanalysis EOF principal component time series during both advance and retreat. The same analysis was conducted on each member of the model historical SIE data to determine whether the simulated influence of the leading atmospheric modes on SIE reflects the reanalysis.

\section{Results}

\subsection{Observed atmosphere-sea ice interactions}

In this section, the relationship between Antarctic sea ice and atmospheric conditions during the seasons of ice advance and retreat is examined. As previously discussed, interactions during the seasons of ice advance and retreat are the key focus of this study, as it is during these periods that the link between Antarctic sea ice to atmospheric forcing is strongest (Stammerjohn et al., 2008; Renwick et al., 2012). Figure 1 shows the zero-lag correlation of sector-integrated SIE with SLP, following Raphael and Hobbs (2014). Sea ice in individual sectors responds to different atmospheric patterns, and the response also varies between the seasons of ice advance and retreat. Many of these response patterns are similar to those found by Raphael and Hobbs (2014) upon whose approach this method is based; however, the use of seasonal weighting in this analysis (which was not included in the previous study) yielded different patterns for some sectors and seasons.

During ice advance, SIE in the Ross/Amundsen sector is negatively correlated with SLP over West Antarctica (Fig. 1a). The negative correlation here indicates that increasing SIE in this sector is associated with a deepening of the atmospheric pattern shown. This negative correlation pattern persists into the retreat season (Fig. 1b) but shifts towards the Ross Sea and expands to incorporate a circumpolar component. The shape and location of the correlation pattern is indicative of an ASL component, which in its mean position is centred close to $110^{\circ} \mathrm{W}$, while the circumpolar, zonally symmetric component reflects a SAM-like "see-saw" of pressure anomalies between the high and mid-latitudes (Karoly, 1990; Gong and Wang, 1999; Thompson and Wallace, 2000; Marshall, 2003). The longitudinal position of the ASL, which shifts towards the west during the winter and towards the east in summer (Turner et al., 2013b), is strongly influenced by the polarity of SAM and is itself a strong influence on the climate of West Antarctica (Hosking et al., 2013). Raphael et al. (2015) demonstrated the link between large-scale atmospheric circulation changes, particularly their effect on geostrophic flow, and the climatic influence of the meridional and zonal location of the ASL. The correlations in Fig. 1a and $b$ indicate that sea ice in the Ross/Amundsen sector responds to surface air flow changes brought about by the ASL during the period of advance, and that the SAM dominates the sector during the period of retreat.

Correlations between SIE and SLP in the Amundsen/Bellingshausen sector during advance are almost the inverse of those in the Ross/Amundsen sector during the same season, with positive correlations centred over the Amundsen Sea and extending from the Ross Sea towards the Bellingshausen Sea (Fig. 1c). This indicates that the ASL is the dominant large-scale atmospheric driver of interannual sea ice variability for the Amundsen/Bellingshausen sector during the period of ice advance, and is consistent with previous analysis showing the influence of the ASL on the meridional wind field in the West Antarctic region (Hosking et al., 2013). During the retreat season, the correlation pattern remains in a similar area but weakens, contracting northwards and towards the Ross Sea (Fig. 1d). This does not follow the longitudinal shift of the ASL described above, but rather reflects the spatial pattern of the PSA (Mo and Paegle, 2001). This atmospheric pattern is generally taken to reflect the relationship between ENSO and the high latitudes, and indicates the influence of tropical forcing on sea ice in the Amundsen/Bellingshausen sector during ice retreat, in agreement with Raphael and Hobbs (2014).

In the Weddell sector during ice advance, there is no significant correlation between SIE and SLP (Fig. 1e), indicating that there is no distinct large-scale atmospheric influence on the interannual variability of sea ice in this sector and season. Rather, the variability of sea ice in this region during ice advance is more likely driven by alternative factors such as synoptic-scale weather systems, intrinsic variability, or the ocean. During retreat, the positive correlation pattern between sea ice variability in the Weddell sector with atmospheric variability over the Amundsen and Bellingshausen seas indicates the influence of the ASL (Fig. 1f). The inverse sign of the correlations compared with ASL influence in the Ross/Amundsen sector during the same season indicates that as the atmospheric circulation pattern deepens, sea ice extent in the Weddell Sea decreases. This reflects the implied circulation of the ASL in this region, where stronger southerly winds over the Ross Sea result in the northward transport and reduced melt of sea ice in this region and stronger northerlies over the north of the Antarctic Peninsula confining ice in the Weddell Sea and increasing melt (Liu et al., 2004). The apparently differing drivers affecting ice advance and retreat in the Weddell sector agrees with recent findings by Matear et al. (2015) that sea ice variability in the western Atlantic region is likely driven by combined wind variability from synoptic and large-scale atmospheric patterns.

The King Hakon VII sector during advance (Fig. 1g) shows negative correlations over the Amundsen and Bellingshausen seas, indicating the influence of the ASL on sea ice variability in this sector. However, during retreat the pattern 

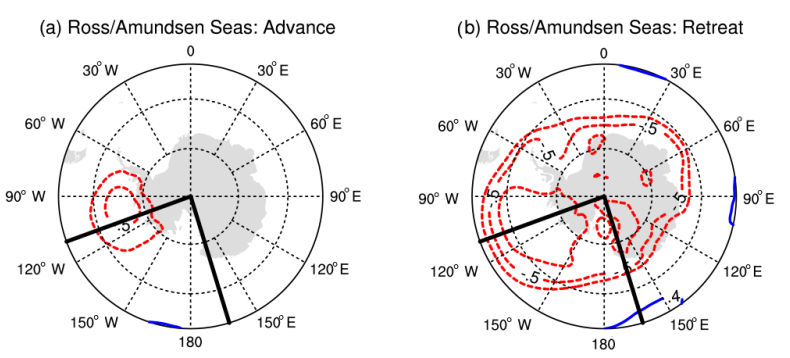

(c) Amundsen/Bellingshausen Seas: Advance

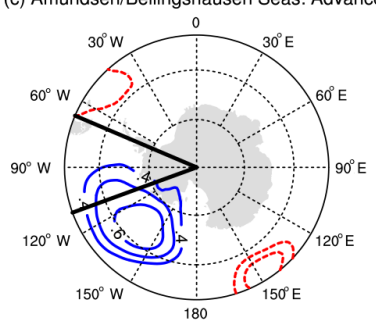

(d) Amundsen/Bellingshausen Seas: Retreat
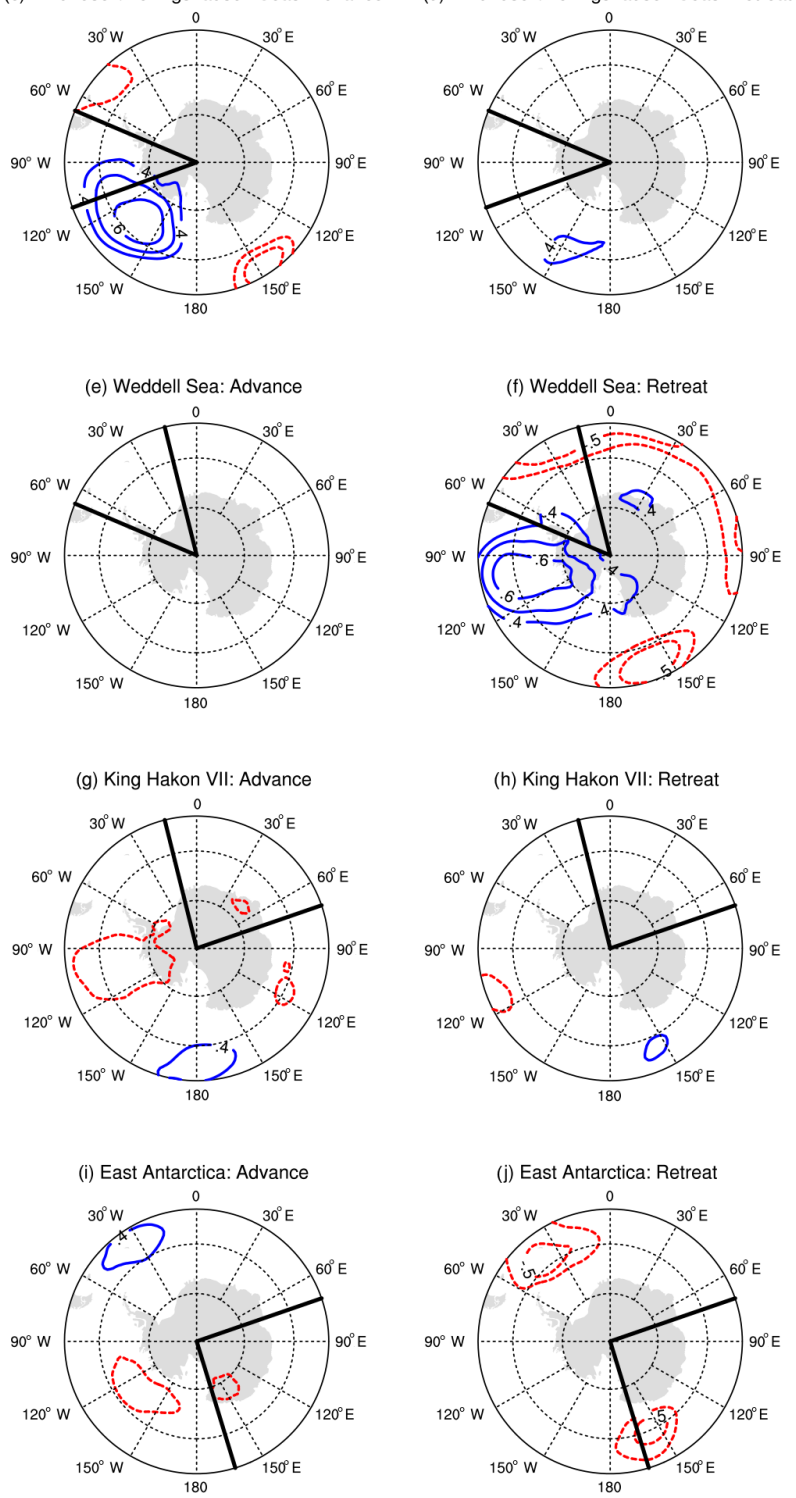

Figure 1. Cross-correlations (significant at $95 \%$ ) of observed SIE with ERA-Interim SLP from 1979 to 2014 during advance (a, c, e, $\mathbf{g}, \mathbf{i})$ and retreat $(\mathbf{b}, \mathbf{d}, \mathbf{f}, \mathbf{h}, \mathbf{j})$. Red dotted contours indicate negative correlations, where a decrease in sea level pressure is associated with an increase in sea ice extent; blue contours indicate positive correlations, where a decrease in sea level pressure is associated with a decrease in sea ice extent. Black lines show sector boundaries. disappears, with no large-scale atmospheric influence on sea ice variability visible (Fig. 1h). This suggests that variability in retreating sea ice in this region is more sensitive to other factors such as weather and a small ENSO forcing as suggested by Matear et al. (2015).

Correlations in the East Antarctica sector do not reveal the SAM-like patterns found by Raphael and Hobbs (2014) during either advance or retreat (Fig. $1 \mathrm{i}$ and $\mathrm{j}$ ), but rather SIE is negatively correlated to SLP over the eastern Ross and Amundsen seas and positively correlated to the South Atlantic during advance. During retreat, the negative correlations shift to an area between 130 and $180^{\circ} \mathrm{E}$ and are stronger, while the positive correlations in the South Atlantic become negative. This agrees with previous studies showing that annual SIE in roughly this same region is influenced more by cyclonic activity around the western Pacific Ocean rather than a large-scale atmospheric pattern (Matear et al., 2015; Turner et al., 2015).

In summary, large-scale atmospheric circulation patterns do not appear to be a dominant driver of sea ice variability in all sectors and seasons. The ASL is the dominant force in the Ross/Amundsen, Amundsen/Bellingshausen, and King Hakon VII sectors during advance and the Weddell sector during retreat. SAM-sea ice interactions occur in the Ross/Amundsen sector during ice retreat.

\subsection{Simulated atmosphere-sea ice interactions}

The analysis presented for the observations in Fig. 1 was repeated for each piControl simulation for the CMIP5 models. The correlations for each model were compared to the observed correlations in each sector and season to determine how closely the models represent the observed pattern of atmosphere-sea ice interactions (Fig. 2). A high pattern correlation value indicates that the simulated interactions closely reflected the observed interactions, while a value near zero indicates that the two were substantially different. A high negative correlation value means that the pattern was similar, but the correlation was the inverse sign to the observations. These comparisons only measure the extent to which the observed spatial pattern was replicated in the models, not whether the magnitude of the interactions in the models is similar to that of the observations. The correlation between simulated patterns and observed patterns during advance is plotted horizontally, while the correlations during retreat are plotted vertically for each sector (correlation maps for individual models can be seen in Fig. S2).

Simulated SIE and SLP correlation patterns most closely reflect observed patterns during the season of advance. The percentage of variance in the observed pattern that can be accounted for by each simulated pattern can be obtained by calculating the coefficient of determination, $r^{2}$, which is the square of the pattern correlation value. During advance, 5 of the 16 models simulate a correlation pattern in the Ross/Amundsen sector that can account for at least $80 \%$ 
(a) Ross/Amundsen Seas

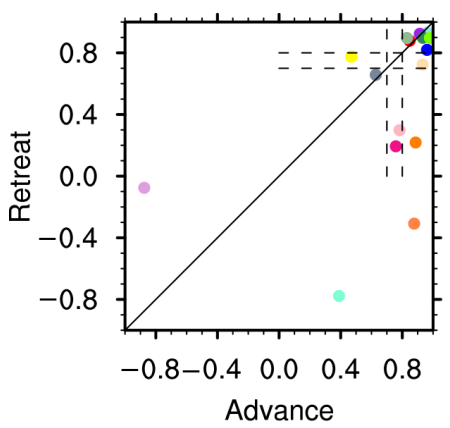

(c) Weddell Sea

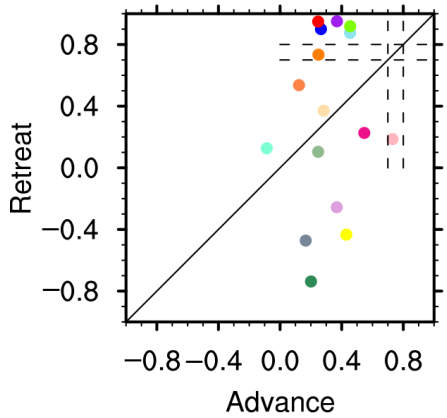

(e) East Antarctica

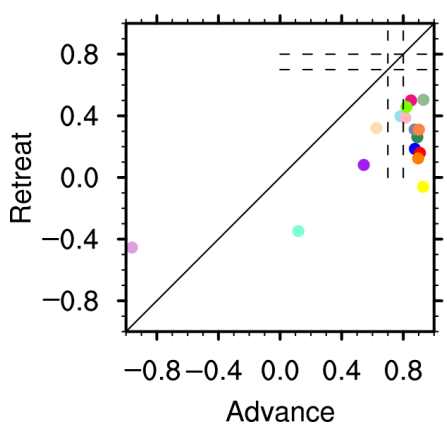

(b) Amundsen/Bellingshausen Seas

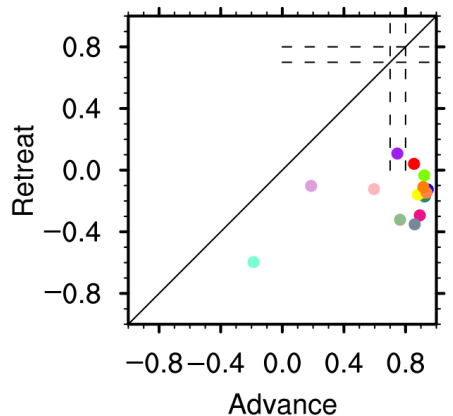

(d) King Hakon VII
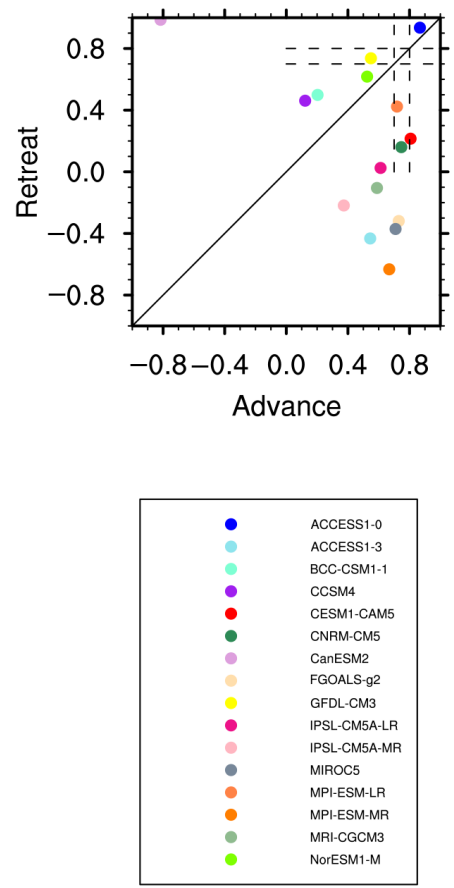

Figure 2. Pattern correlation values comparing observations and CMIP5 piControl ensemble correlation maps of SLP and SIE in the (a) Ross/Amundsen seas; (b) Amundsen/Bellingshausen seas; (c) Weddell Sea; (d) King Hakon VII; and (e) East Antarctica sectors. Dotted lines at 0.7 and 0.9 show the point at which the coefficient of determination, $r^{2}$, is equal to 50 or $80 \%$, respectively. The diagonal line indicates where correlations for both seasons would be in agreement.

of the spatial variance in the observed pattern, while 12 of the 16 models simulate a pattern that can account for over $50 \%$ of the observed pattern. Correlations are even stronger in the Amundsen/Bellingshausen sector during advance, with 7 of the 16 models simulating a correlation pattern with an $r^{2}$ value of at least $80 \%$ of the observed pattern, and 13 of the 16 producing a pattern with an $r^{2}$ value of over $50 \%$ of the observed pattern. For East Antarctica and King Hakon VII, the number of model simulations with patterns that can account for at least $50 \%$ of the observed pattern is 12 and 4 , respectively.
However, during the retreat season, the simulated patterns are less consistent with the observed patterns. Only in the Weddell sector do more simulations produce patterns that can account for over $50 \%$ of the variance in the observed pattern during retreat (5) than in advance (0). In the Ross/Amundsen sector, simulations during ice retreat continue to reflect the observations reasonably well, though not as strongly as in advance. In the remaining sectors, especially East Antarctica and Amundsen/Bellingshausen, the simulations largely do not capture the observed SIE and SLP correlations during retreat. 
(a) RAS: advance

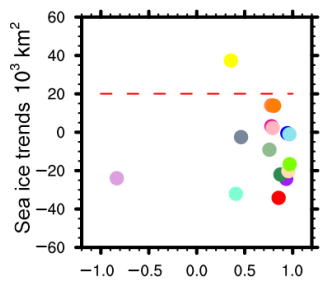

(c) ABS: advance

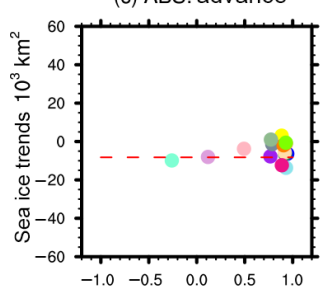

(e) WS: advance

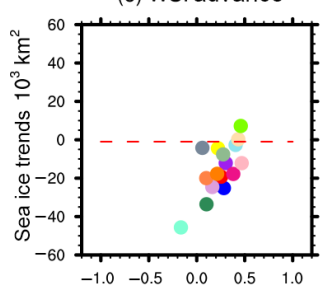

(g) $\mathrm{KH}$ : advance

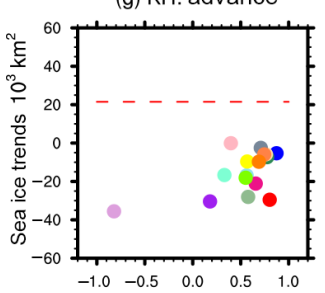

(i) EA: advance

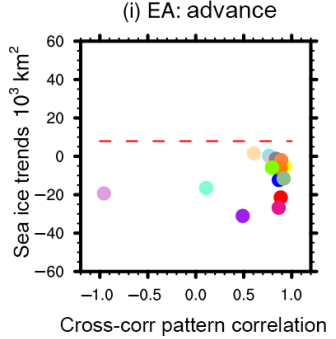

(b) RAS: retreat

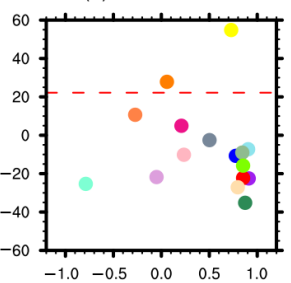

(d) ABS: retreat

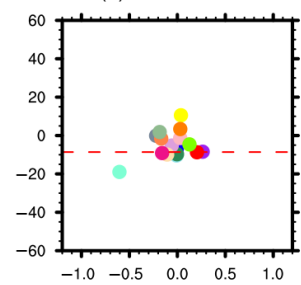

(f) WS: retreat

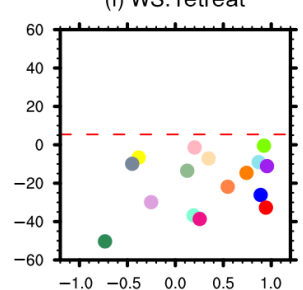

(h) $\mathrm{KH}$ : retreat
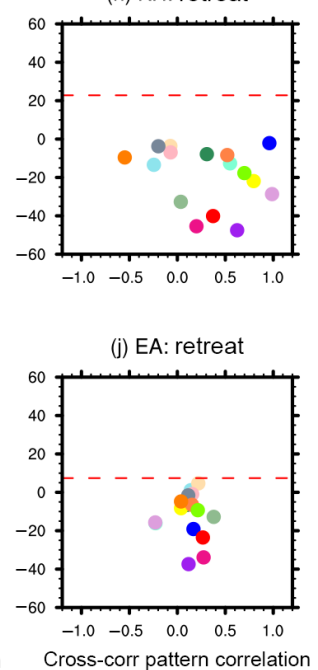

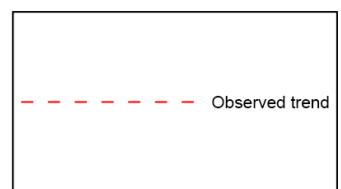

\begin{tabular}{|ll|}
\hline & ACCESS1-0 \\
ACCESS1-3 \\
BCC-CSM1-1 \\
CCSM4 \\
CESM1-CAM5 \\
CNRM-CM5 \\
CanESM2 \\
FGOALS-g2 \\
GFDL-CM3 \\
IPSL-CM5A-LR \\
IPSL-CM5A-MR \\
MIROC5 \\
MPI-ESM-LR \\
MPI-ESM-MR \\
MRI-CGCM3 \\
NorESM1-M \\
\hline
\end{tabular}

Figure 3. Pattern correlation values comparing observations and CMIP5 model correlation maps of SLP and SIE against the model historical (1979-2005) SIE trends for: Ross/Amundsen seas (RAS) during (a) advance and (b) retreat; Amundsen/Bellingshausen seas (ABS) during (c) advance and (d) retreat; Weddell Sea (WS) during (e) advance and (f) retreat; King Hakon VII (KH) during (g) advance and (h) retreat; and East Antarctica (EA) during (i) advance and (j) retreat.

These results have shown that the models have varying levels of success in representing the atmosphere's impact on sea ice variability. It is particularly interesting that the models reproduce these atmosphere-sea ice interactions more strongly during the period of advance than during retreat, especially given the strong representations in the Ross/Amundsen and
Amundsen/Bellingshausen sectors, and that ice advance is the period during which model trends of SIE in these sectors deviate most significantly from the observed trends (Hobbs et al., 2015, 2016). Given the discrepancy between simulated and observed SIE trends, it is pertinent to consider whether the extent to which models represent observed atmospheric 
variability also impacts upon their representation of sea ice trends. To examine this issue, the same pattern correlation values discussed above are plotted for each model against that model's SIE trend for that sector and season, which is calculated using the ensemble average of the model's historical simulation (Fig. 3). The observed trend for each sector and season is plotted as a red dotted line. There does not appear to be a strong relationship between higher pattern correlation values (indicating close agreement between the model correlation maps and that of the reanalysis) and the proximity of model SIE trends to observed SIE trends in each sector and season. This is most clearly noticeable in the Ross/Amundsen, Amundsen/Bellingshausen, and East Antarctica sectors, particularly during advance (Fig. 3a, c, and i). In these sectors, although the representation of the reanalysis correlations is generally strong, a wide spread in trend values is also evident. These results suggest that a model with an interannual sea ice-atmosphere interaction pattern that closely represents the observed pattern will not necessarily also produce realistic sea ice trends.

\subsection{Model representation of large-scale atmospheric modes}

The leading atmospheric mode produced by the EOF analysis of ERA-Interim SLP data clearly displays the spatial pattern of the circumpolar SAM and the associated ASL, explaining $36 \%$ of the variance in SLP during advance and $40 \%$ during retreat (Fig. $4 \mathrm{a}$ and $\mathrm{b}$ ). The second and third eigenvectors illustrate the spatial pattern of the PSA (Mo and Ghil, 1987). These two PSA modes were added together to produce a single mode representing the influence of tropical forcing on the high southern latitudes, in order to compare observation-based and simulated tropical impacts on sea ice (Fig. 4c and d). The combined PSA EOF accounts for $27 \%$ of the variance in SLP during advance and $21 \%$ during retreat. The EOF analysis was then conducted on the individual ensemble members of each model, revealing the forced climate response of each model member. Individual ensemble member EOFs can be seen in Fig. S3. These were then correlated with the EOFs from ERA-Interim (Fig. 5).

The results are explained using two metrics. The first metric, correlation values, is used to indicate the strength of the simulated representation of the spatial pattern seen in the reanalysis. A correlation value close to 1 indicates good representation of the pattern, while values near 0 indicate little resemblance between the two. A second metric was created by dividing the amount of atmospheric variance explained by the model EOF by the amount of variance explained by the observation-based pattern, creating a ratio of the percentage of variance explained. A ratio of $1: 1$, which would appear on the dotted curved reference line, indicates that the amount of variance explained by the pattern in the models is the same as the amount explained in the observation-based pattern, while a higher or lower ratio, appearing above or be-
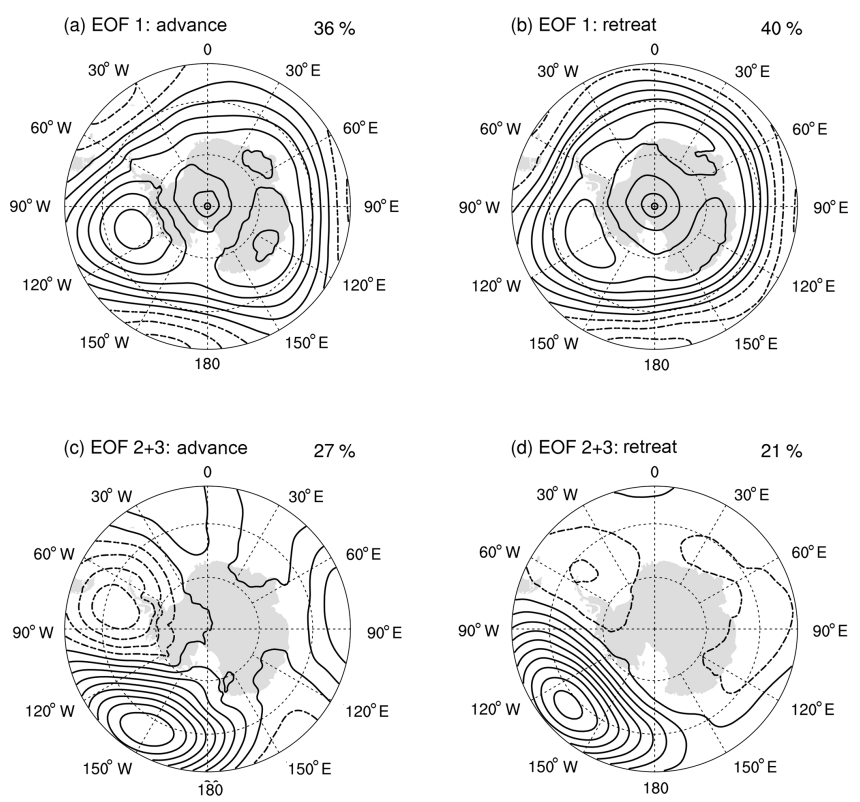

Figure 4. Eigenvectors of ERA-Interim SLP (1979-2014) in the Southern Ocean for advance $(\mathbf{a}, \mathbf{c})$ and retreat $(\mathbf{b}, \mathbf{d})$. Numbers at top right indicate the percentage of variance in the data explained by each pattern.

low the dotted reference line, indicates whether the model is over-representing or under-representing the influence of this atmospheric pattern.

The first EOF shows loose clustering across the ensemble members, indicating general agreement within individual models in their representation of the spatial pattern of the SAM during both ice advance and ice retreat (Fig. 5a and b). Of the 73 individual ensemble members used in the study, 68 during advance and 45 during retreat produced a reasonable spatial pattern of the SAM as evidenced by correlation values greater than 0.7 . No ensembles during either advance or retreat obtained correlation values of 0.5 or less. In terms of the percentage of atmospheric variance explained by the simulated patterns compared with that of the observationbased pattern, the patterns of 45 ensemble members during advance and 60 during retreat account for a ratio of variance higher than the $1: 1$ ratio that indicates agreement with the variance explained by the reanalysis. This shows that the relative influence of SAM is overestimated in a large proportion of models, particularly during the season of ice retreat, consistent with Haumann et al. (2014). The response of sea ice to SAM is stronger during retreat than during advance, so the amplification of the simulated influence of SAM occurs most strongly when the SAM matters most to simulated SIE.

The combined second and third EOFs show a large spread of correlations across the ensemble members during both ice advance and ice retreat (Fig. $5 c$ and d). The spread occurs across the ensemble members generally, and also across the ensemble members of individual models. An implicit as- 
(a) EOF1 - advance

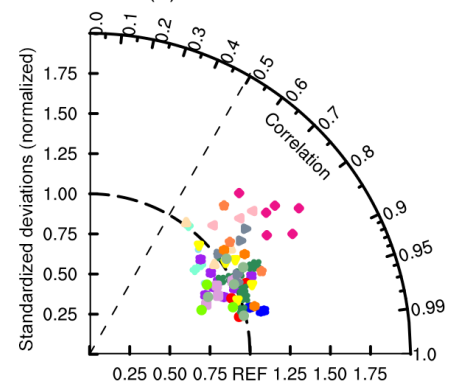

(c) EOF2+3-advance

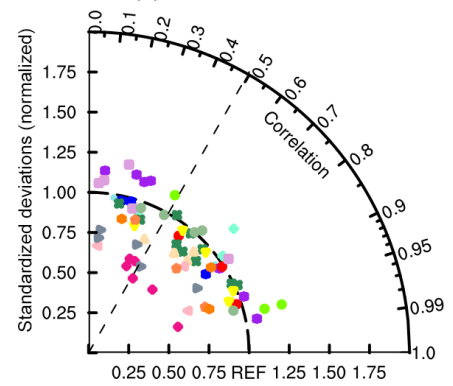

(b) EOF1 - retreat

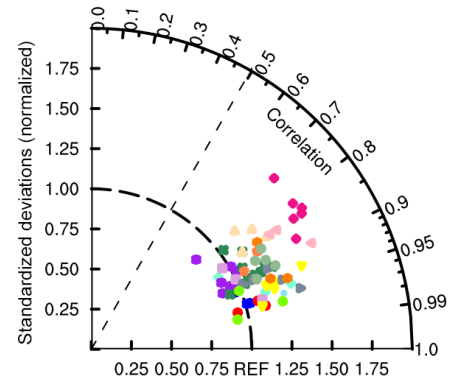

(d) EOF2+3- retreat

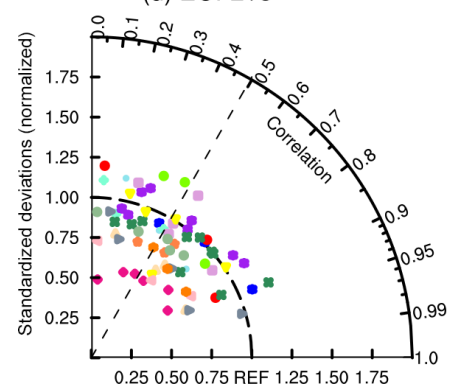

- ACCESS1-0

ACCESS1-3

BCC-CSM1-1

CCSM4

CESM1-CAM5

CNRM-CM5

CanESM2

FGOALS-g2

GFDL-CM3

IPSL-CM5A-LR

IPSL-CM5A-MR

MIROC5

MPI-ESM-LR

MPI-ESM-MR

MRI-CGCM3

NorESM1-M

Figure 5. Taylor diagram showing the pattern correlation value (curved outer line) comparing historical CMIP5 ensemble and ERA-Interim SLP eigenvectors, and the percentage of variance explained by each pattern in the historical ensembles as a ratio of the observations for EOF 1 during advance (a) and retreat (b) and the combined EOFs 2 and 3 during advance (c) and retreat (d).

sumption in this comparison is that the PSA observed during the period 1979-2014 is a stable mode over longer timescales than are observed; a caveat could be that the PSA may change over long timescales, and differences between the spatial representation of PSA in different ensemble members may represent the influence of multi-decadal variability.

During advance, 32 ensemble members produce a PSA pattern with a correlation greater than 0.7 , while during retreat only 21 ensemble members achieve this. Meanwhile, 29 ensembles during advance and 60 during retreat produce patterns that have correlations with the reanalysis of less than 0.5. This indicates that a substantial proportion of ensemble members - indeed, the majority of ensemble members during retreat - do not produce a reasonable representation of tropical teleconnection in the high southern latitudes. Furthermore, the PSA patterns for 54 of the ensemble members during advance and 51 during retreat explain a lower percentage of atmospheric variance than the reanalysis. The overarching implication here is that for most ensembles, the SAM mode dominates atmospheric variability, creating a stronger zonal pattern than is seen in the reanalysis. The variance explained by the tropical mode is comparatively weak in these ensembles as a result, and the simulated patterns of the PSA are generally weak representations of the observation-based PSA pattern. This is perhaps unsurprising, given that even basic ENSO characteristics are known to be weakly represented in the CMIP5 models (Guilyardi et al., 2012; Bel- lenger et al., 2014), and therefore the high-latitude teleconnections would be expected to be likewise underestimated.

These metrics test the strength of SAM relative to the PSA in each model, but do not indicate the amount of variability of each mode in the models compared with observed variability. To test this, the variance of each ensemble member principal component time series corresponding to each of the three EOFs was compared to the variance of the same principal component time series in the reanalysis data during the seasons of sea ice advance and retreat (Fig. 6). The results show that the absolute variance of both SAM and PSA is substantially less than observed variability in these modes across both seasons, despite the models overestimating the percentage of variance in the data explained by the SAM. The close clustering of the ensemble members relative to the reanalysis indicates that these ensemble members generally underestimate variability in large-scale atmospheric modes. However, though simulated large-scale atmospheric variability appears to be underestimated, it is well known that sea ice variability in the SH is generally too high in the models (Zunz et al., 2013).

The relative influence of the SAM and PSA on SIE in the historical ensembles as compared to ERA-Interim is shown in Fig. 7. Correlations of the EOFs and SIE using piControl ensembles (not shown here) were consistent with the correlations using historical ensembles for both advance and retreat, as the detrending of historical ensembles reveals interannual variability rather than the forced response of the his- 

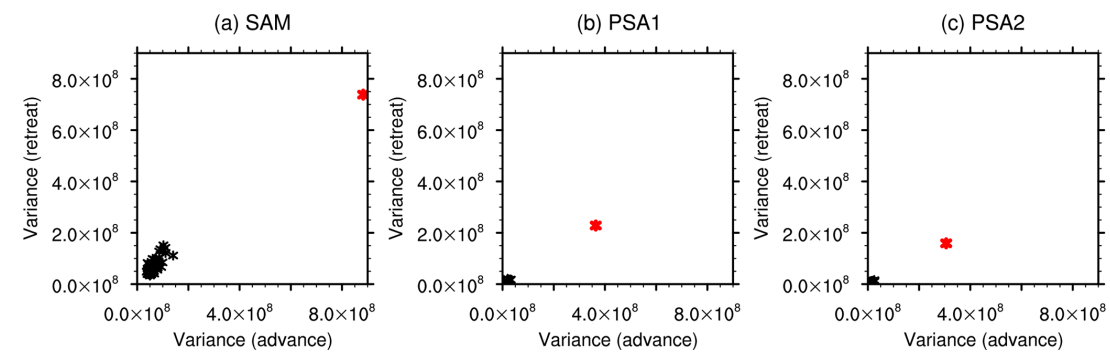

Figure 6. Absolute variance during sea ice advance and retreat of the corresponding principal component time series for (a) SAM, (b) PSA1, and (c) PSA2. The black markers indicate CMIP5 ensemble members; the red markers indicates ERA-Interim reanalysis.

(a) SAM - advance (historical)

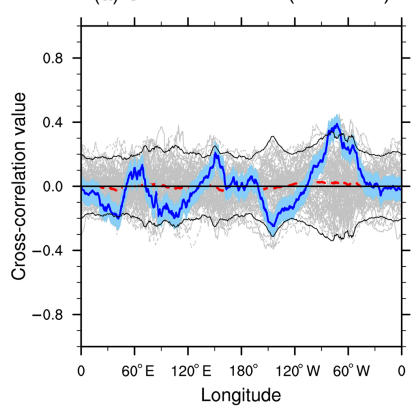

(c) PSA - advance (historical)

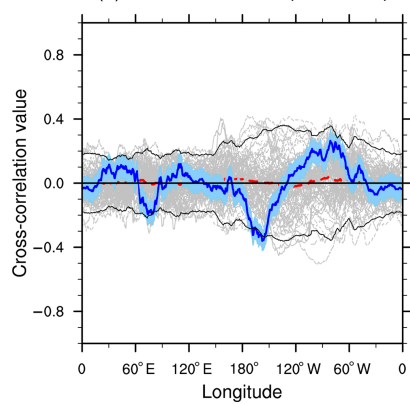

(b) SAM - retreat (historical)

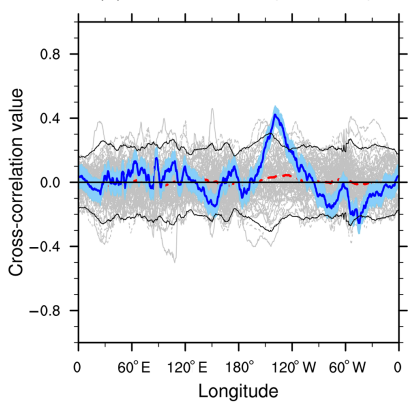

(d) PSA - retreat (historical)

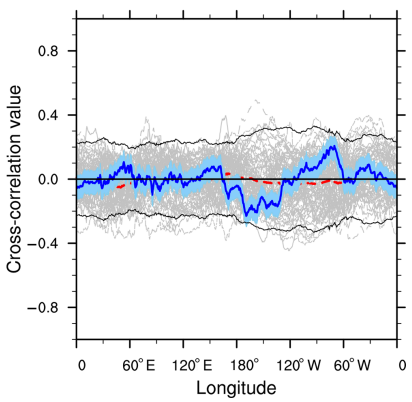

Figure 7. Cross-correlation of SIE with historical (1979-2005) SAM during (a) advance and (b) retreat, with historical (19792005) PSA during (c) advance and (d) retreat. The blue line indicates observation-based correlations, with the light blue shading depicting the $95 \%$ confidence interval. The red dotted line shows the multi-model mean, and the pale grey lines show individual model correlations. The thin black lines at the edge of the grey lines shows 1.96 standard deviation from the simulations at each longitude point, while the horizontal black line shows the zero line for reference.

torical members. Observed correlations between SAM and SIE, shown by the dark blue line, indicate the strong regional heterogeneity in this relationship in several sectors around Antarctica during both seasons (Hosking et al., 2013; Turner et al., 2013b, 2016; Fogt and Wovrosh, 2015; Raphael et al., 2015). However, modelled interactions between SAM and SIE, shown by the grey lines, indicate no clear regional discrimination, particularly during retreat when the strong correlation over the Ross/Amundsen sector falls outside of

1.96 standard deviation (as shown by the black line towards the top of the grey lines). The multi-model mean (shown in red) shows an overall zonal pattern with weak correlations between SAM and SIE that are largely consistent across the range of longitudes, while \pm 1.96 standard deviation indicates a similarly zonal pattern. The correlations of simulated PSA and SIE in historical ensembles (Fig. 6c and d) likewise lack regional distinction, with a largely zonally symmetric pattern during retreat and a similar zonal pattern during advance that has a slight increase in strength around the Amundsen/Bellingshausen sectors. Once again, the multimodel mean of historical ensembles is zonal with very weak correlations, and the \pm 1.96 standard deviation indicates that the models do not represent the spatial variability of this mode and its interaction with sea ice that are known to be important in the observational record (Simmonds and Jacka, 1995; Kwok and Comiso, 2002; Turner, 2004; Yuan, 2004; Simpkins et al., 2012).

\section{Discussion and conclusions}

By expanding upon the approach of Raphael and Hobbs (2014), this study has provided insight into the representation of interannual sea ice-atmosphere interactions in CMIP5 models. The metrics used in this study showed that piControl simulations had surprisingly good skill in representing the observed atmosphere-sea ice interactions in several sectors. Interestingly, the representation of these interactions more closely reflected observations during the season of sea ice advance than during retreat. The results from Sect. 4.2 provide evidence that during advance, the models largely capture the response of sea ice to atmospheric drivers. In the advance season, the modelled sea ice trends diverge most significantly from observed trends, particularly in the Ross/Amundsen and Amundsen/Bellingshausen sectors where the highestmagnitude trends are also observed (Hobbs et al., 2015, 2016). Simulated representations of atmosphere-sea ice interactions during advance which more closely reflect observed interactions do not appear to lead to an improved representation of sea ice trends. It has been shown that sea ice trends in some sectors during advance are driven by changes 
in the previous retreat season (Holland, 2014). If observed and modelled sea ice trends during advance are sensitive to changes in interactions between sea ice and the atmosphere during retreat, this could explain why simulated sea ice trends in some sectors are most significantly different from the observations during advance despite the close representation of observed interannual atmosphere-ice interactions during this season.

From earlier work, it is known that the atmosphere-toocean heat flux accounts for only up to $50 \%$ of the required heating for the observed sea ice melt between 60 and $70^{\circ} \mathrm{S}$ (Gordon, 1981). Thus, the remainder of the melting process is likely to be from heat exchange between the deep ocean and surface waters and the absorption of solar radiation through leads in the sea ice, driving peripheral melt of floe edges. It is therefore expected that the role of the atmosphere in driving sea ice variability may be diminished during retreat, and that atmosphere-ice interactions alone are unlikely to be sufficient to explain the observed interactions between the ocean, sea ice, and atmosphere during retreat. As a major driver of sea ice retreat, the role of the ocean in the melting of sea ice during this season warrants further scrutiny in models and observations.

It has previously been established that the observed influence of SAM and ENSO on high southern latitude climate is strongest during the late southern winter and spring (Jin and Kirtman, 2010; Simpkins et al., 2012). However, during both sea ice advance and retreat, the majority of historical simulations overestimated the relative importance of the SAM and underestimated that of the PSA. The amount of variance in the models explained by the PSA is generally weak compared with the representation of SAM, which is also much more zonal than observed. The interannual relationship between SAM and sea ice also lacks regional variation, which is known to be substantial particularly in the Ross, Amundsen, Bellingshausen, and Weddell seas. The relationship between the PSA and sea ice likewise does not show strong regional variation. If the simulated zonal atmospheric influence overwhelms meridional influence, it follows that simulated sea ice variability would become more zonally symmetric as a result. However, the absolute magnitude of largescale atmospheric variability being generally very low in the models compared with observations, while simulated sea ice variability is known to be generally too high, suggests that large-scale atmospheric modes in the models may explain less of the discrepancy between modelled and observed sea ice trends than previously thought.

The absence of a strong observed influence of large-scale atmospheric modes in several sectors indicates that while large-scale atmospheric variability is a strong and important influence on sea ice in some sectors, it may not be the dominant driver of sea ice change around all of Antarctica. Other possible drivers for some sectors include sub-synoptic-scale wind forcing such as the variability of the Ross Sea polynya driven by katabatic surges, drainage and barrier winds over the Ross Sea (Bromwich et al., 1998), atmospheric variance not explained by the major modes, or the ocean.

Data availability. NSIDC monthly sea ice concentration data can be obtained at doi:10.7265/N55M63M1. ERA-Interim monthly sea level pressure data can be obtained at http://apps.ecmwf. int/. CMIP5 data are available at https://pcmdi.llnl.gov/projects/ esgf-1ln1/. Data analysis and visualization was performed using NCL (doi:10.5065/D6WD3XH5).

\section{The Supplement related to this article is available online at doi:10.5194/tc-11-789-2017-supplement.}

Competing interests. The authors declare that they have no conflict of interest.

Acknowledgements. The authors thank Marilyn Raphael, Rob Massom, and two anonymous reviewers for their helpful comments in the preparation of this manuscript. Serena Schroeter was supported by an Australian Government Research Training Program Scholarship through the University of Tasmania/CSIRO Quantitative Marine Science Programme, and CMIP5 data management was supported by the Australian Research Council Centre of Excellence for Climate System Science. We acknowledge the World Climate Research Programme's Working Group on Coupled Modeling, which is responsible for CMIP, and we thank the climate modelling groups (listed in Table 1) for producing and making available their model output. For CMIP the U.S. Department of Energy's Program for Climate Model Diagnosis and Intercomparison provides coordinating support and led development of software infrastructure in partnership with the Global Organization for Earth System Science Portals. This work was supported by the Australian Government's Cooperative Research Centres Programme through the Antarctic Climate and Ecosystems Cooperative Research Center (ACE CRC), and contributes to AAS Project 4116.

Edited by: D. Notz

Reviewed by: two anonymous referees

\section{References}

Armour, K. C., Marshall, J., Scott, J. R., Donohoe, A., and Newsom, E. R.: Southern Ocean warming delayed by circumpolar upwelling and equatorward transport, Nat. Geosci., 9, 549-554, doi:10.1038/ngeo2731, 2016.

Arora, V., Scinocca, J., Boer, G., Christian, J., Denman, K., Flato, G., Kharin, V., Lee, W., and Merryfield, W.: Carbon emission limits required to satisfy future representative concentration pathways of greenhouse gases, Geophys. Res. Lett., 38, L05805, doi:10.1029/2010GL046270, 2011.

Bellenger, H., Guilyardi, É., Leloup, J., Lengaigne, M., and Vialard, J.: ENSO representation in climate models: from CMIP3 to CMIP5, Clim. Dynam., 42, 1999-2018, 2014. 
Bentsen, M., Bethke, I., Debernard, J. B., Iversen, T., Kirkevåg, A., Seland, Ø., Drange, H., Roelandt, C., Seierstad, I. A., Hoose, C., and Kristjánsson, J. E.: The Norwegian Earth System Model, NorESM1-M - Part 1: Description and basic evaluation of the physical climate, Geosci. Model Dev., 6, 687-720, doi:10.5194/gmd-6-687-2013, 2013.

Bernades Pezza, A., Rashid, H. A., and Simmonds, I.: Climate links and recent extremes in Antarctic sea ice, high-latitude cyclones, Southern Annular Mode and ENSO, Clim. Dynam., 38, 57-73, 2012.

Bi, D., Dix, M., Marsland, S. J., O'Farrell, S., Rashid, H., Uotila, P., Hirst, A., Kowalczyk, E., Golebiewski, M., and Sullivan, A.: The ACCESS coupled model: description, control climate and evaluation, Australian Meteorological and Oceanographic Journal, 63, 41-64, 2013.

Bindoff, N. L., Stott, P. A., AchutaRao, K. M., Allen, M. R., Gillett, N., Gutzler, D., Hansingo, K., Hegerl, G., Hu, Y., Jain, S., Mokhov, I. I., Overland, J., Perlwitz, J., Sebbari, R., and Zhang, X.: Detection and Attribution of Climate Change: from Global to Regional, in: Climate Change 2013: The Physical Science Basis. Contribution of Working Group I to the Fifth Assessment Report of the Intergovernmental Panel on Climate Change, edited by: Stocker, T. F., Qin, D., Plattner, G.-K., Tignor, M., Allen, S. K., Boschung, J., Nauels, A., Xia, Y., Bex, V., and Midgley, P. M., Cambridge University Press, Cambridge, United Kingdom and New York, NY, USA, 2013.

Bromwich, D., Liu, Z., Rogers, A. N., and Van Woert, M. L.: Winter atmospheric forcing of the Ross Sea polynya, in: Ocean, Ice, and Atmosphere: Interactions at the Antarctic Continental Margin, edited by: Jacobs, S. S. and Weiss, R. F., American Geophysical Union, Washington, D.C., 1998.

Bromwich, D. H., Nicolas, J. P., and Monaghan, A. J.: An assessment of precipitation changes over Antarctica and the Southern Ocean since 1989 in contemporary global reanalyses, J. Climate, 24, 4189-4209, 2011.

Dee, D. P., Uppala, S. M., Simmons, A. J., Berrisford, P., Poli, P., Kobayashi, S., Andrae, U., Balmaseda, M. A., Balsamo, G., Bauer, P., Bechtold, P., Beljaars, A. C. M., van de Berg, L., Bidlot, J., Bormann, N., Delsol, C., Dragani, R., Fuentes, M., Geer, A. J., Haimberger, L., Healy, S. B., Hersbach, H., Hólm, E. V., Isaksen, L., Kållberg, P., Köhler, M., Matricardi, M., McNally, A. P., Monge-Sanz, B. M., Morcrette, J. J., Park, B. K., Peubey, C., de Rosnay, P., Tavolato, C., Thépaut, J. N., and Vitart, F.: The ERA-Interim reanalysis: configuration and performance of the data assimilation system, Q. J. Roy. Meteor. Soc., 137, 553-597, 2011

Ding, Q., Steig, E. J., Battisti, D. S., and Küttel, M.: Winter warming in West Antarctica caused by central tropical Pacific warming, Nat. Geosci., 4, 398-403, 2011.

Ferreira, D., Marshall, J., Bitz, C. M., Solomon, S., and Plumb, A.: Antarctic ocean and sea ice response to ozone depletion: A twotime-scale problem, J. Climate, 28, 1206-1226, 2015.

Fogt, R. L. and Bromwich, D. H.: Decadal Variability of the ENSO Teleconnection to the High-Latitude South Pacific Governed by Coupling with the Southern Annular Mode, J. Climate, 19, 979997, 2006.

Fogt, R. L. and Wovrosh, A. J.: The relative influence of tropical sea surface temperatures and radiative forcing on the Amund- sen Sea Low, J. Climate, 28, 8540-8555, doi:10.1175/JCLI-D15-0091.1, 2015.

Fogt, R. L., Perlwitz, J., Monaghan, A. J., Bromwich, D. H., Jones, J. M., and Marshall, G. J.: Historical SAM Variability. Part II: Twentieth-Century Variability and Trends from Reconstructions, Observations, and the IPCC AR4 Models, J. Climate, 22, 53465365, 2009.

Fogt, R. L., Bromwich, D. H., and Hines, K. M.: Understanding the SAM influence on the South Pacific ENSO teleconnection, Clim. Dynam., 36, 1555-1576, 2010.

Gent, P. R., Danabasoglu, G., Donner, L. J., Holland, M. M., Hunke, E. C., Jayne, S. R., Lawrence, D. M., Neale, R. B., Rasch, P. J., and Vertenstein, M.: The community climate system model version 4, J. Climate, 24, 4973-4991, 2011.

Gillett, N. P. and Thompson, D. W. J.: Simulation of Recent Southern Hemisphere Climate Change, Science, 302, 273-275, 2003.

Gong, D. and Wang, S.: Definition of Antarctic oscillation index, Geophys. Res. Lett., 26, 459-462, 1999.

Gordon, A. L.: Seasonality of Southern Ocean sea ice, J. Geophys. Res., 4193-4197, 1981.

Griffies, S. M., Winton, M., Donner, L. J., Horowitz, L. W., Downes, S. M., Farneti, R., Gnanadesikan, A., Hurlin, W. J., Lee, H.-C., and Liang, Z.: The GFDL CM3 coupled climate model: characteristics of the ocean and sea ice simulations, J. Climate, 24, 3520-3544, 2011.

Guilyardi, E., Bellenger, H., Collins, M., Ferrett, S., Cai, W., and Wittenberg, A.: A first look at ENSO in CMIP5, Clivar Exchanges, 17, 29-32, 2012.

Hall, A. and Visbeck, M.: Synchronous Variability in the Southern Hemisphere Atmosphere, Sea Ice, and Ocean Resulting from the Annular Mode, J. Climate, 15, 3043-3057, 2002.

Harangozo, S. A.: A search for ENSO teleconnections in the west Antarctic Peninsula climate in austral winter, Int. J. Climatol. 20, 663-679, 2000.

Haumann, F. A., Notz, D., and Schmidt, H.: Anthropogenic influence on recent circulation-driven Antarctic sea ice changes, Geophys. Res. Lett., 41, 8429-8437, 2014.

Hobbs, W. R., Bindoff, N. L., and Raphael, M. N.: New perspectives on observed and simulated Antarctic sea ice extent trends using optimal fingerprinting techniques, J. Climate, 28, 15431560, 2015.

Hobbs, W. R., Massom, R., Stammerjohn, S., Reid, P., Williams, G., and Meier, W.: A review of recent changes in Southern Ocean sea ice, their drivers and forcings, Global Planet. Change, 143, 228250, 2016.

Holland, P. R.: The seasonality of Antarctic sea ice trends, Geophys. Res. Lett., 41, 4230-4237, 2014.

Holland, P. R. and Kwok, R.: Wind-driven trends in Antarctic seaice drift, Nat. Geosci., 5, 872-875, 2012.

Hosking, J. S., Orr, A., Marshall, G. J., Turner, J., and Phillips, T.: The influence of the amundsen-bellingshausen seas low on the climate of West Antarctica and its representation in coupled climate model simulations, J. Climate, 26, 6633-6648, 2013.

Jin, D. and Kirtman, B. P.: How the annual cycle affects the extratropical response to ENSO, J. Geophys. Res., 115, D06102, doi:10.1029/2009JD012660, 2010.

Jungclaus, J., Fischer, N., Haak, H., Lohmann, K., Marotzke, J., Matei, D., Mikolajewicz, U., Notz, D., and Storch, J.: Characteristics of the ocean simulations in the Max Planck Institute Ocean 
Model (MPIOM) the ocean component of the MPI-Earth system model, J. Adv. Model. Earth Syst., 5, 422-446, 2013.

Karoly, D. J.: Southern Hemisphere Circulation Features Associated with El Niño-Southern Oscillation Events, J. Climate, 2, 1239-1252, 1989.

Karoly, D. J.: The role of transient eddies in low-frequency zonal variations of the Southern Hemisphere circulation, Tellus A, 42, 41-50, 1990.

Kohyama, T. and Hartmann, D. L.: Antarctic Sea Ice Response to Weather and Climate Modes of Variability, J. Climate, 29, 721$741,2016$.

Kwok, R. and Comiso, J. C.: Southern Ocean Climate and Sea Ice Anomalies Associated with the Southern Oscillation, J. Climate, 15, 487-501, 2002.

Kwok, R., Comiso, J., Lee, T., and Holland, P.: Linked trends in the South Pacific sea ice edge and Southern Oscillation Index, Geophys. Res. Lett., 43, 10295-10302, doi:10.1002/2016GL070655, 2016.

Lachlan-Cope, T. A., Connolley, W. M., and Turner, J.: The role of the non-axisymmetric antarctic orography in forcing the observed pattern of variability of the Antarctic climate, Geophys. Res. Lett., 28, 4111-4114, 2001.

Lefebvre, W. and Goosse, H.: An analysis of the atmospheric processes driving the large-scale winter sea ice variability in the Southern Ocean, J. Geophys. Res., 113, C02004, doi:10.1029/2006JC004032, 2008.

Lefebvre, W., Goosse, H., Timmermann, R., and Fichefet, T.: Influence of the Southern Annular Mode on the sea ice-ocean system, J. Geophys. Res., 109, C09005, doi:10.1029/2004JC002403, 2004.

Li, L., Lin, P., Yu, Y., Wang, B., Zhou, T., Liu, L., Liu, J., Bao, Q., $\mathrm{Xu}, \mathrm{S}$., and Huang, W.: The flexible global ocean-atmosphereland system model, Grid-point Version 2: FGOALS-g2, Adv. Atmos. Sci., 30, 543-560, 2013.

Limpasuvan, V. and Hartmann, D. L.: Eddies and the annular modes of climate variability, Geophys. Res. Lett., 26, 3133-3136, 1999.

Liu, J., Curry, J. A., and Martinson, D. G.: Interpretation of recent Antarctic sea ice variability, Geophys. Res. Lett., 31, L02205, doi:10.1029/2003GL018732, 2004.

Mahlstein, I., Gent, P. R., and Solomon, S.: Historical Antarctic mean sea ice area, sea ice trends, and winds in CMIP5 simulations, J. Geophys. Res., 118, 5105-5110, 2013.

Marshall, G. J.: Trends in the Southern Annular Mode from Observations and Reanalyses, J. Climate, 16, 4134-4143, 2003.

Marshall, G. J., Orr, A., Van Lipzig, N. P., and King, J. C.: The impact of a changing Southern Hemisphere Annular Mode on Antarctic Peninsula summer temperatures, J. Climate, 19, 53885404, 2006.

Marshall, J., Armour, K. C., Scott, J. R., Kostov, Y., Hausmann, U., Ferreira, D., Shepherd, T. G., and Bitz, C. M.: The ocean's role in polar climate change: asymmetric Arctic and Antarctic responses to greenhouse gas and ozone forcing, Philos. T. Roy. Soc. A, 372, 20130040, doi:10.1098/rsta.2013.0040, 2014.

Massom, R., Reid, P., Stammerjohn, S., Raymond, B., Fraser, A., and Ushio, S.: Change and variability in East Antarctic sea ice seasonality, 1979/80-2009/10, PloS one, 8, e64756, doi:10.1371/journal.pone.0064756, 2013.

Massom, R. A., Stammerjohn, S. E., Lefebvre, W., Harangozo, S. A., Adams, N., Scambos, T. A., Pook, M. J., and Fowler,
C.: West Antarctic Peninsula sea ice in 2005: Extreme ice compaction and ice edge retreat due to strong anomaly with respect to climate, J. Geophys. Res., 113, C02S20, doi:10.1029/2007JC004239, 2008.

Matear, R. J., O'Kane, T. J., Risbey, J. S., and Chamberlain, M.: Sources of heterogeneous variability and trends in Antarctic sea-ice, Nature Communications, 6, 8656, doi:10.1038/ncomms9656, 2015.

Meier, W., Fetterer, F., Savoie, M., Mallory, S., Duerr, R., and Stroeve, J.: NOAA/NSIDC Climate Data Record of Passive Microwave Sea Ice Concentration, Version 2, National Snow and Ice Center, Boulder, Colorado, USA, 2015.

Mignot, J. and Bony, S.: Presentation and analysis of the IPSL and CNRM climate models used in CMIP5, Clim. Dynam., 40, 20892089, 2013.

Mo, K. C.: Relationships between Low-Frequency Variability in the Southern Hemisphere and Sea Surface Temperature Anomalies, J. Climate, 13, 3599-3610, 2000.

Mo, K. C. and Ghil, M.: Statistics and Dynamics of Persistent Anomalies, J. Atmos. Sci., 44, 877-902, 1987.

Mo, K. C. and Paegle, J. N.: The Pacific-South American modes and their downstream effects, Int. J. Climatol., 21, 1211-1229, 2001.

Neale, R.: Description of the NCAR Community Atmospheric Model (CAM 5.0), NCAR Techical Note, NCAR/TN-486+STR, 212 pp., 2010.

Parkinson, C. L. and Cavalieri, D. J.: Antarctic sea ice variability and trends, 1979-2010, The Cryosphere, 6, 871-880, doi:10.5194/tc-6-871-2012, 2012.

Raphael, M. N.: The influence of atmospheric zonal wave three on Antarctic sea ice variability, J. Geophys. Res., 112, D12112, doi:10.1029/2006JD007852, 2007.

Raphael, M. N. and Hobbs, W.: The influence of the large-scale atmospheric circulation on Antarctic sea ice during ice advance and retreat seasons, Geophys. Res. Lett., 41, 5037-5045, 2014.

Raphael, M. N., Marshall, G. J., Turner, J., Fogt, R. L., Schneider, D., Dixon, D. A., Hosking, J. S., Jones, J. M., and Hobbs, W. R.: The Amundsen Sea Low: Variability, Change, and Impact on Antarctic Climate, B. Am. Meteorol. Soc., 97, 12 pp. doi:10.1175/BAMS-D-14-00018.1, 2015.

Renwick, J. A., Kohout, A., and Dean, S.: Atmospheric forcing of Antarctic sea ice on intraseasonal time scales, J. Climate, 25, 5962-5975, 2012.

Schneider, D. P., Deser, C., and Okumura, Y.: An assessment and interpretation of the observed warming of West Antarctica in the austral spring, Clim. Dynam., 38, 323-347, 2011.

Sen Gupta, A. and England, M. H.: Coupled ocean-atmosphere-ice response to variations in the Southern Annular Mode, J. Climate, 19, 4457-4486, 2006.

Simmonds, I. and Jacka, T. H.: Relationships between the Interannual Variability of Antarctic Sea Ice and the Southern Oscillation, J. Climate, 8, 637-647, 1995.

Simpkins, G. R., Ciasto, L. M., Thompson, D. W. J., and England, M. H.: Seasonal relationships between large-scale climate variability and antarctic sea ice concentration, J. Climate, 25, 54515469, 2012.

Stammerjohn, S., Massom, R., Rind, D., and Martinson, D.: Regions of rapid sea ice change: An inter-hemispheric 
seasonal comparison, Geophys. Res. Lett., 39, L06501, doi:10.1029/2012GL050874, 2012.

Stammerjohn, S. E., Martinson, D. G., Smith, R. C., Yuan, X., and Rind, D.: Trends in Antarctic annual sea ice retreat and advance and their relation to El Niño-Southern Oscillation and Southern Annular Mode variability, J. Geophys. Res., 113, C03S90, doi:10.1029/2007JC004269, 2008.

Taylor, K. E., Stouffer, R. J., and Meehl, G. A.: A summary of the CMIP5 experiment design, PCDMI Report, 33 pp., 2009.

Taylor, K. E., Stouffer, R. J., and Meehl, G. A.: An overview of CMIP5 and the experiment design, B. Am. Meteorol. Soc., 93, 485-498, 2012.

Thompson, D. W. J. and Solomon, S.: Interpretation of Recent Southern Hemisphere Climate Change, Science, 296, 895-899, 2002.

Thompson, D. W. J. and Wallace, J. M.: Annular Modes in the Extratropical Circulation. Part I: Month-to-Month Variability, J. Climate, 13, 1000-1016, 2000.

Thompson, D. W. J., Solomon, S., Kushner, P. J., England, M. H., Grise, K. M., and Karoly, D. J.: Signatures of the Antarctic ozone hole in Southern Hemisphere surface climate change, Nat. Geosci., 4, 741-749, 2011.

Thompson, D. W. J., Wallace, J. M., and Hegerl, G. C.: Annular Modes in the Extratropical Circulation. Part II: Trends, J. Climate, 13, 1018-1036, 2000.

Turner, J.: The El Niño-southern oscillation and Antarctica, Int. J. Climatol., 24, 31 pp., 2004.

Turner, J., Bracegirdle, T. J., Phillips, T., Marshall, G. J., and Scott Hosking, J.: An initial assessment of antarctic sea ice extent in the CMIP5 models, J. Climate, 26, 1473-1484, 2013a.

Turner, J., Phillips, T., Hosking, J. S., Marshall, G. J., and Orr, A.: The Amundsen Sea low, Int. J. Climatol., 33, 1818-1829, 2013b.

Turner, J., Hosking, J. S., Bracegirdle, T. J., Marshall, G. J., and Phillips, T.: Recent changes in Antarctic sea ice, Philos. T. Roy. Soc. A, 373, 20140163, doi:10.1098/rsta.2014.0163, 2015.

Turner, J., Hosking, J. S., Marshall, G. J., Phillips, T., and Bracegirdle, T. J.: Antarctic sea ice increase consistent with intrinsic variability of the Amundsen Sea Low, Clim. Dynam., 46, 23912402, doi:10.1007/s00382-015-2708-9, 2016.

van Lipzig, N. P. M., Marshall, G. J., Orr, A., and King, J. C.: The Relationship between the Southern Hemisphere Annular Mode and Antarctic Peninsula Summer Temperatures: Analysis of a High-Resolution Model Climatology, J. Climate, 21, 1649-1668, 2008 .
Voldoire, A., Sanchez-Gomez, E., y Mélia, D. S., Decharme, B., Cassou, C., Sénési, S., Valcke, S., Beau, I., Alias, A., and Chevallier, M.: The CNRM-CM5. 1 global climate model: description and basic evaluation, Clim. Dynam., 40, 2091-2121, 2013.

Watanabe, M., Suzuki, T., O'ishi, R., Komuro, Y., Watanabe, S., Emori, S., Takemura, T., Chikira, M., Ogura, T., and Sekiguchi, M.: Improved climate simulation by MIROC5: mean states, variability, and climate sensitivity, J. Climate, 23, 6312-6335, 2010.

Xiao-Ge, X., Tong-Wen, W., and Jie, Z.: Introduction of CMIP5 experiments carried out with the climate system models of Beijing Climate Center, Advances in Climate Change Research, 4, 4149, 2013.

Yu, L., Zhang, Z., Zhou, M., Zhong, S., Lenschow, D. H., Gao, Z., Wu, H., Li, N., and Sun, B.: Interpretation of recent trends in Antarctic sea ice concentration, J. Appl. Remote Sens., 5, 053557, doi:10.1117/1.3643691, 2011.

Yuan, X.: ENSO-related impacts on Antarctic sea ice: A synthesis of phenomenon and mechanisms, Antarct. Sci., 16, 415-425, 2004.

Yuan, X. and Li, C.: Climate modes in southern high latitudes and their impacts on Antarctic sea ice, J. Geophys. Res., 113, C06S91, doi:10.1029/2006JC004067, 2008.

Yuan, X. and Martinson, D. G.: The Antarctic dipole and its predictability, Geophys. Res. Lett., 28, 3609-3612, 2001.

Yukimoto, S., Adachi, Y., Hosaka, M., Sakami, T., Yoshimura, H., Hirabara, M., Tanaka, T. Y., Shindo, E., Tsujino, H., and Deushi, M.: A new global climate model of the Meteorological Research Institute: MRI-CGCM3 - Model description and basic performance, J. Meteorol. Soc. Jpn., 90A, 23-64, 2012.

Zunz, V., Goosse, H., and Massonnet, F.: How does internal variability influence the ability of CMIP5 models to reproduce the recent trend in Southern Ocean sea ice extent?, The Cryosphere, 7, 451-468, doi:10.5194/tc-7-451-2013, 2013.

Zwally, H. J., Comiso, J. C., Parkinson, C. L., Campbell, W. J., and Carsey, F. D.: Antarctic sea ice, 1973-1976: Satellite passivemicrowave observations, NASA, Washington, DC, Technical Report, NASA-SP-459, 222 pp., 1983.

Zwiers, F. W. and von Storch, H.: Taking serial correlation into account in tests of the mean, J. Climate, 8, 336-351, 1995. 